\title{
Erosion and sedimentation as processes controlling the BSR-derived heat flow on the Eastern Nankai margin
}

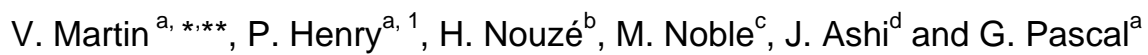

${ }^{a}$ Ecole Normale Supérieure de Paris, Laboratoire de Géologie UMR 8538, 24 Rue Lhomond, 75231, Paris Cedex 05, France

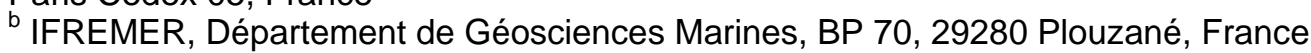

${ }^{\mathrm{c}}$ Ecole des Mines de Paris, Centre de Recherche en Géophysique, 35 rue St. Honoré, 77305, Fontainebleau Cedex, France

d Ocean Research Institute, University of Tokyo, 1-15-1 Minamidai, Nakano, Tokyo 164-8639, Japan

*: Corresponding author : Total, Centre Scientifique et Technique Jean Feger, Avenue Larribau, 64018, Pau Cedex, , France. Tel.: +33-559-83-63-19; fax: +33-559-83-65-90.

** Now at: Collège de France, Europole de l'Arbois, BP80, 13545 Aix en Provence Cedex 04, France.

\begin{abstract}
:
In 2000, a 3D MCS survey was carried out on the Eastern Nankai Trough. A strong and widespread bottom-simulating reflector (BSR) was observed and mapped after a preserved amplitude 3D prestack migration of the seismic data. We use this BSR to calculate a heat flow map over the 3D survey area. This map presents some high and low heat flow areas, that cannot be correlated to known active wedge faults and previously observed fluid venting sites. Since the heat flow anomalies are not correlated to known major faults or fluid venting sites, large fluid circulation is not likely to explain the varying BSR-derived heat flow distribution. In order to explain this heat flow distribution quantitatively, we calculate the rates of erosion and sedimentation that are necessary to create these anomalies. These rates are in good agreement with observations on seismic profiles, and are locally consistent with a sedimentation rate calculated from slope basin depth, and reflect the distribution of erosion, landsliding and deposition on the margin slope. We therefore propose that the observed BSR-derived heat flow anomalies are mainly due to active erosion and sedimentation, and that heat flow distribution on the margin section of the $3 \mathrm{D}$ survey is controlled by surface processes. Fluid migration could occur where a BSR is absent, but is probably episodic or limited where a BSR is present, and does not affect the BSR-derived heat flow in this part of the margin. These surface processes are the consequence of the tectonic and seismic activity of the wedge and are influenced by the subduction of a wide oceanic ridge below the Eastern Nankai margin.
\end{abstract}

Keywords: bottom-simulating reflector; heat flow; surface processes; Eastern Nankai margin 


\section{Introduction}

Heat flow and its causes have been widely studied over several active margins. It provides significant constraints to understand processes occuring within these margins. Whereas the effect of thermal advection and friction influences the thermal regime of the margins over a large spatial scale [14], more local processes may also occur, that modify significantly the heat flow. Several authors pointed out that the heat flow sometimes presents strong local anomalies in comparison with its theorical value. These anomalies are generally interpreted as the consequence of fluid circulation, both in the trench $[1,5]$ and in accretionary wedges [6-9]. On the Eastern Nankai margin, several fluid venting sites have been extensively observed at the outcrop of active faults [10-12], but the influence of the water expulsion from these sites on the heat flow is still in question. In this area, a detailed mapping of the heat flow is necessary to ensure the position of the anomalies and their relationships with faults along which fluids circulate. This is the approach we apply here.

We used the map of the bottom simulating reflector (BSR) on the Eastern Nankai margin to calculate a heat flow on a 3D multichannel seismic survey location, where several erosionnal and slumping features have been observed. The BSR is a reverse polarity reflector on seismic profiles that is interpreted as the base of the gas hydrates stability zone [13]. The depth of this reflector may be used to calculate the temperature at BSR depth from the hydrate dissociation curve, and then used to calculate a thermal gradient and a heat flow [14-16].

This method has been widely used in several terrestrial and marine environments, and gives heat flow values that are generally consistent with direct probe measurements, within an error range reaching $15-20 \%$ in worst cases. Heat flow derived from BSR depth is less sensitive to short timescale changes in sea-bottom water temperature than probe measurements, and thus may be more reliable for water depth of less than $2000 \mathrm{~m}$ (see for example [17]). The obtained heat flow presents some areas of very high heat

flow. Some of them are located in erosive channels, and one corresponds to a landslide initiation area. This landslide provides an insight on the process by which a shallow BSR, and subsequently high heat 
flow, is obtained over part of the 3D survey area. Positive BSR-derived heat flow anomalies can not be here correlated to any known major fault in the accretionary wedge or fluid seepage, and several areas have an anomalously low heat flow. Furthermore, the survey was carried out on a transect where fluid manifestations have been observed, but are discreet in comparison to other areas of the margin. These observations are not consistent with the expulsion of warm fluid as the main cause of the anomalies inferred from the BSR depth, with respect to a margin-scale advection-conduction model. Another explanation has then to be found.

Surface processes, such as erosion and sedimentation, may cause heat flow anomalies. The thermal aspect of these processes has thoroughly been studied in several sedimentary basins [18-20]. On continental margins, these processes are generally linked to subsidence or tectonic uplift. To investigate the role of these processes in our study area in the heat flow variations, we use a 1D thermal model to calculate average erosion and deposition rates that would explain the observed anomalies.

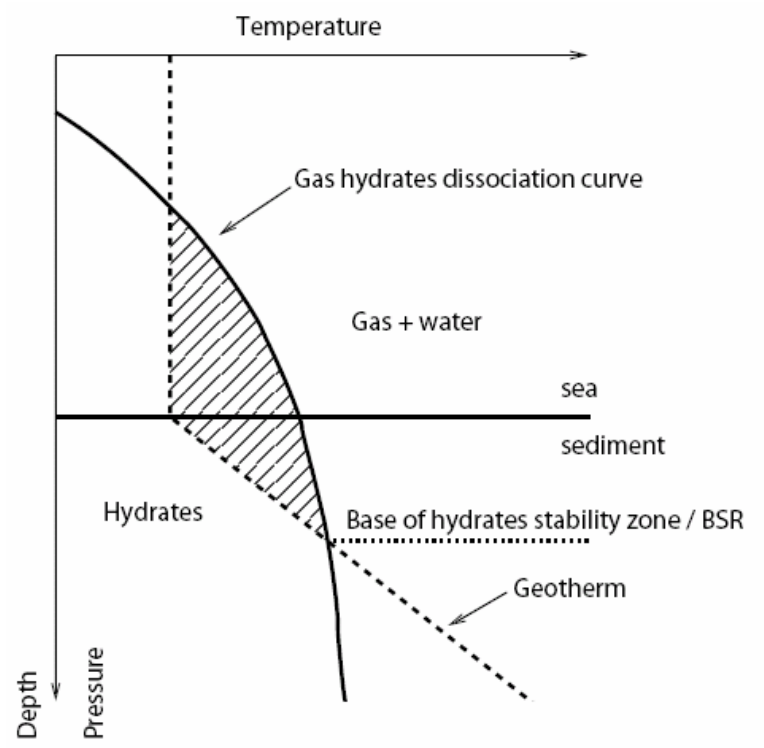

Figure 1. Schematic zone of gas hydrates stability (after [13]). Gas hydrates are stable due to high pressure at depth and low temperature in the gray area. The geothermal gradient causes a temperature elevation deeper in the ground, and causes hydrates dissociation that creates a BSR. 


\section{3D structure of the BSR}

In this study, we used 3D seismic images of the Eastern Nankai Trough (figure 2), acquired over the accretionary wedge in 2000 during the french-japanese SFJ survey [21]. Processing of the data was performed using the 3D Kirchhoff preserved amplitude prestack depth migration algorithm [22] with an acquisition footprints regularisation scheme [23]. The velocity model was obtained after a migration velocity analysis. The validity of the velocity model was ensured by the flatness of the BSR in migrated common reflection gathers [24]. Over the BSR area, the wedge bathymetry can be divided into four domains, from the shallowest to the deepest. The first corresponds to the flat forearc basin landward from the Kodaiba fault, and is slightly tilted around a relief, the Daiichi Tenryu knoll. The second part is located between the Kodaiba fault and the slopebreak. The bathymetry is affected there by channels and faults. The third part is the slope between the upper slopebreak and the Tokai fault location [25]. The Tokai fault is considered as the limit between an old wedge and an active wedge [26]. The last part is a slope basin on top of the active wedge. The BSR is present nearly everywhere in the 3D box area, except under a major part of the slope, around the Kodaiba fault and under the Daiichi Tenryu knoll, where the seafloor is too shallow to enable hydrate formation. A double BSR was also observed and its possible origin discussed by [27]. The BSR map is presented in figure 3. It disappears or has a very weak amplitude around the Kodaiba fault but is not significantly raised towards the seafloor around this location on the seismic profiles where it is identified crossing the fault (see figure 3). On another profile eastward from the 3D box and parallel to it, the BSR is continuous and not uplifted under the Kodaiba fault surface location, which indicates that no or only very little warm fluid circulation presently takes place along the fault in this area (east of $\left.137^{\circ} 30^{\prime} \mathrm{E}\right)$.

Further in seaward direction, the BSR is discontinuous and is closer to the surface in the upper part of the slope. Downslope, it is strong and nearly flat under the slope basin. The amplitude of the BSR is generally strong in the forearc basin, but is locally weak in a thick sedimentary layer. The weakness of the BSR amplitude coincides with the disappearance of the double BSR and the presence of a flat spot 
under the BSR. This phenomenon could be due to a different sediment nature and a possibly different porosity in this sedimentary layer.

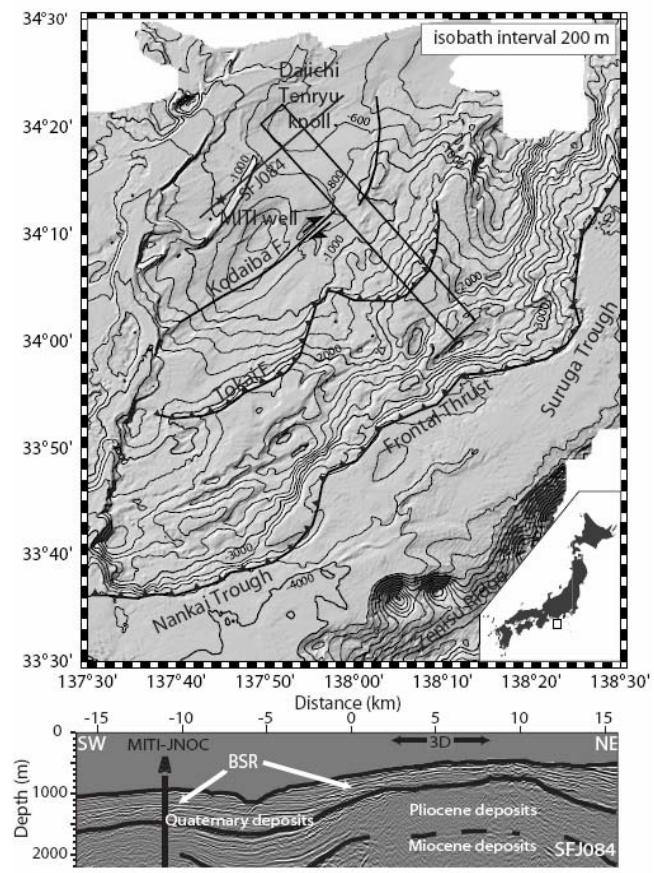

Figure 2. Up: map of the SFJ survey area. High-resolution profiles and the 3D-box location are drawn in black and gray. The main faults are represented after [25]. The MITI well location is represented with a star. ODP leg 190 wells lie west of the represented area. Down: schematic cross-section from a seismic profile from the MITI well to the 3D survey area.

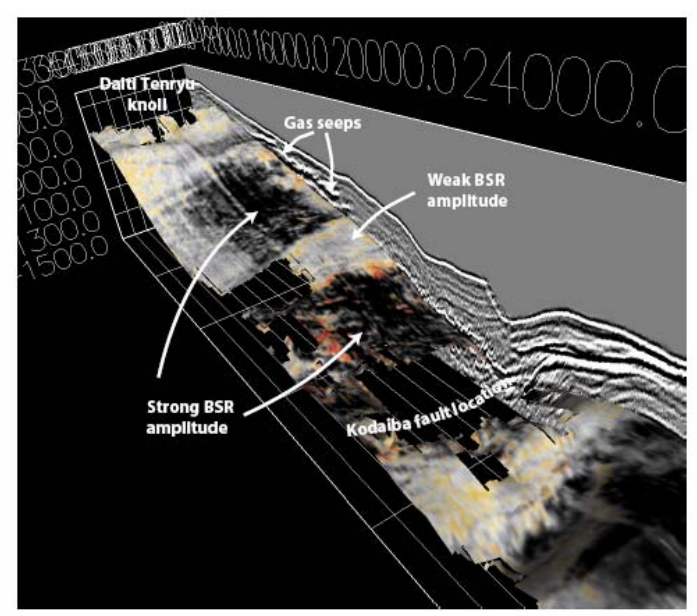

Figure 3. BSR tridimensionnal view on the forearc basin zone. The colorscale corresponds to the BSR amplitude, after a 3D Kirchhoff preserved amplitude prestack depth migration. Weak amplitudes (light gray) probably correspond to a change in lithology. The BSR is present on the left of the area crossed by the Kodaiba fault, and is not affected by the fault. Gas seeps in the stable hydrates zones, that can be recognized because of their negative polarity, can be observed on the seismic profile on the right. 


\section{Heat flow calculation}

The calculation of the heat flow from the BSR is generally done by assuming a purely vertical thermal heat transfer hypothesis [15]. Presence of small reliefs or depressions affect the temperature field and the temperature gradient is not purely vertical. We therefore smoothed the bathymetric and BSR depth maps using a gaussian filter of $1 \mathrm{~km}$ diameter $(2 \sigma)$, that corresponds to the maximum spatial wavelength of the strongest bathymetric irregularities. In that way, we reduce the horizontal component of the temperature gradient, but the obtained heat flow map will correspond to spatially smoothed heat flow values.

The temperature at the BSR can be deduced from the Pressure-Temperature hydrates dissociation curve. Several authors (e. g. $[28,29])$ use a lithostatic pressure value to calculate the temperature , which can be the case in large landslide areas. However, [16] indicate that the pressure to take in account for calculations is the hydrostatic pressure, since it is very uncommon to observe fluid overpressures at the BSR depth in stable sediments. We assumed for the calculation a hydrostatic pore pressure, for two reasons. First, a very high pore pressure would not enable persistency of the slopes of the wedge, and would destabilize the sedimentary column. Second, well data indicate that the temperature conditions at the base of the gas hydrate stability zone are much closer from the dissociation curve if a hydrostatic pressure, rather than lithostatic pressure, is assumed. This is the case in the MITI well on the Nankai margin $\left(14^{\circ} \mathrm{C}\right.$ at a $1245 \mathrm{~m}$ depth [30]), located about $20 \mathrm{~km}$ westward from the survey site on the flat forearc basin (see figure 2).

We calculate the hydrates stability curve by using a set of dissociation temperature measurements [31-33]. The hydrates dissociation curve depends of several factors, the most commonly varying being the gas composition and the water salinity. Local pore and circulating fluid samples taken during submersible dives around Tokai and Kodaiba fault location westward from the study area and on the active wedge and in the MITI well showed that the gas in the sediments have a nearly pure-methane composition, with a nearly constant $\mathrm{CO}_{2}$ composition [34] and very high $\mathrm{CH}_{4} / \mathrm{C}_{2} \mathrm{H}_{6}$ ratios [34,35] at BSR depth. The water 
chlorinity in the sediments was measured on core samples in the MITI well [36,37] and is close to the seawater chlorinity (about $550 \mathrm{mMol} / \mathrm{L}$ ), excepting in sand strata where it is much smaller (100 to 200 $\mathrm{mMol} / \mathrm{L}$ ) because of gas hydrates dissociation during the cores recovery. We used then measurements of dissociation temperature for pure methane in a seawater environment, as recommended by [38], as a model curve. In order to reflect the differences between laboratory measurements and the local environment, this model curve was shifted by $0.3^{\circ} \mathrm{C}$ to fit the dissociation conditions observed in the MITI well (figure 4 left). It can be noted that the starting curve has a similar slope in the $0^{\circ} \mathrm{C}-30^{\circ} \mathrm{C}$ temperature range than curves corresponding to pure water or gases having a non pure methane composition. The used curve is therefore very similar if the model curve is that of pure water composition for example (see figure 4 left), provided that it is shifted to fit the well in-situ measurements. The range of $\mathrm{CO}_{2}$ and $\mathrm{C}_{2} \mathrm{H}_{6}$ measured in the sampled pore water gas content $[34,35]$ has practically no effect on the dissociation curve, therefore the spatial variability of the pore samples in the study area has a very reduced effect on the temperature curve (less than $0.1^{\circ} \mathrm{C}$ ).

Thermal conductivity estimation is an important potential source of errors, because it is variable from one site to the other [16]. [38] showed that presence of gas hydrates in sediments pores has practically no effect on the sediments conductivity, and that the conductivity can be averaged on the sediment column above the BSR. Conductivity measurements on core samples are the best source of data for heat flow calculation, but no conductivity data from the MITI well were available. We then used a conductivity-P waves velocity law extracted from ODP leg 190 well data [39] which is located farther away on the Nankai margin, as suggested by [40], along with the migration velocities used to proces the seismic data. We assume here that the conductivity-P waves velocity law is similar in the ODP leg 190 wells and in the study area. The conductivity-P waves velocity law has a reduced standard deviation of about $17 \%$, which is a high value. However, about one measurement of conductivity every $2 \mathrm{~m}$ was done in the wells. At a $200 \mathrm{~m}$ depth, it means that the statistical standard deviation of the mean value of the thermal conductivity is reduced by a factor of 10 , which is finally less than $2 \%$ of the value $(1.7 \%)$. 
The seafloor temperature is deduced from a annual mean water temperature profile from the Japan Oceanographic Data Center in the Tokai area (figure 4 right). The seasonal variability of the temperature has practicaly no effect on the BSR depth, because the annual cyclic temperature variations do not have the time to diffuse deep in the sediments. However, variations of this temperature for longer periods are likely to occur in shallow water due to long term variability in ocean water circulation. Furthermore, the BSR itself is shallow in the shallow water zones, water temperature changes can thus more rapidly affect the BSR. Therefore the heat flow values obtained in the shallow parts of the 3D box may be biased due to marine currents.
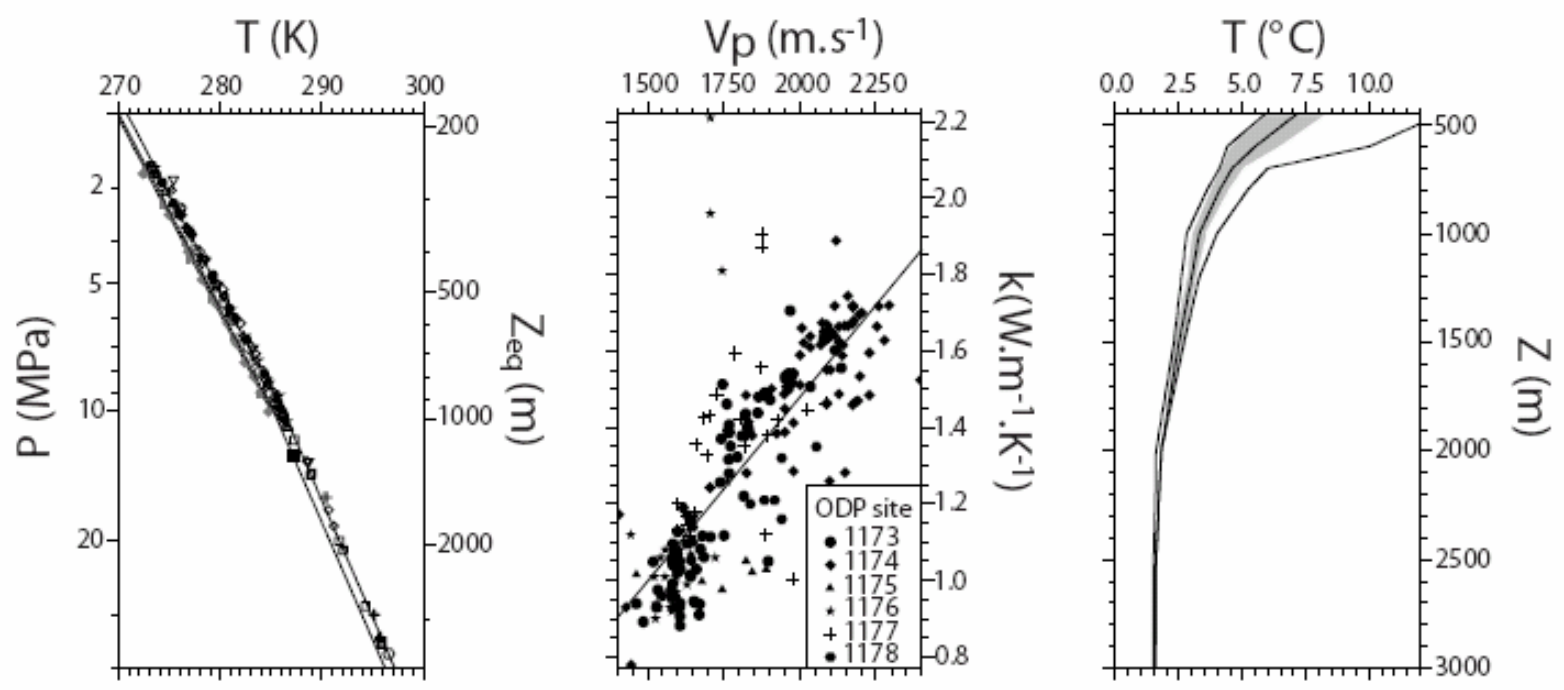

Figure 4. Left: Hydrates dissociation curve deduced from experimental measurements in pure methane and pure water (white symbols) or seawater (gray symbols) conditions, after a compilation of data in [31-33]. The hydrates curve is calibrated to fit the MITI well temperature (black square) at the BSR depth. The scale on the right gives the equivalent depth below sea level. Middle: Velocity-Conductivity relationship from ODP leg 190 [38], used to calculate sediments thermal conductivity in the 3D box. Right: Yearly average sea temperature as a function of depth in the Tokai area, used for the seafloor temperature. The gray area is the 67\% confidence interval (source: Japan Oceanographic Data Center). 


\section{Obtained heat flow}

As stated above, the error on the mean thermal conductivity at a 200 mbsf depth is about $1.7 \%$, and this error statistically decreases with depth. A BSR depth of $200 \mathrm{~m}$ corresponds to a seafloor depth of about $750 \mathrm{~m}$, where the seawater temperature mean error is $0.4^{\circ} \mathrm{C}$. Since the temperature gradient on this area is around $40^{\circ} \mathrm{C} / \mathrm{km}$, a $0.4^{\circ} \mathrm{C}$ discrepancy in the gradient leads to a $5 \%$ error estimate of the temperature gradient over a $200 \mathrm{~m}$ depth. This error also decreases with depth. An increase of the BSR depth leads then to a better reliability of the computed heat flow, regarding the uncertainties on the water temperature and the thermal conductivity. Since the hydrate dissociation curve is considered as reliable, the cumulated error range of the heat flow at a $200 \mathrm{~m}$ depth is about $6.8 \%$, which is considered as acceptable. We therefore consider the heat flow as reliable from a BSR depth of $200 \mathrm{~m}$.

The heat flow computed with the previous dissociation, conductivity and seawater temperature laws is presented in figure 5 . Its values range from 40 to $70 \mathrm{~mW} / \mathrm{m} 2$ in the $3 \mathrm{D}$ box, where a BSR was observed. These values are in good agreement with the heat flow computed from the BSR in a previous study from time migrated profiles [41], although the latter are slightly higher, due to approximations in the time to depth conversion to obtain the temperature at the BSR. It is low $(40-45 \mathrm{~mW} / \mathrm{m} 2)$ on the upper accretionary wedge flat and on a slope basin, where several heat flow probe measurements have been previously made (see figure 5). Probe measurements give a higher value of 70-83 mW/m2 [42,43] to 132 $\mathrm{mW} / \mathrm{m} 2$ [44]. The discrepancy between these probe measurements is probably due to a change in marine currents, or by transient fluid expulsion, both of these effects having little influence on the BSR-derived heat flow. Upper on the wedge, The BSR-derived heat flow is high $(55-70 \mathrm{~mW} / \mathrm{m} 2)$ on the wedge slope upper part in channels, where the strongest heat flow is observed near the slope break. No major fault is known at this location, and no fluid venting observations were reported in the channels. Values of the computed heat flow observed at the location of the main wedge faults in the 3D box, Tokai and Kodaiba faults, are in the mean of observed heat flow range, and are not locally high along the faults where a BSR is observed. Furthermore, no high of the heat flow where a BSR is observed is located around existing 
major faults, which should be the case if rapid fluid expulsion occurred. As a matter of facts, the effect of a strong fluid circulation on the BSR depth has previously been reported by [6,8], and in these cases, the BSR is clearly lifted to the surface, with a maximum uplift at the crossing between the BSR and the fault. The consequence of this uplift is the local strong elevation of the BSR-derived heat flow around the fault. Such an uplift is absent around the Kodaiba area where the BSR is observed and crossing the fault and where fluid venting has been reported. The heat flow variations on the wedge derived from the BSR are thus probably not linked to fluid circulation along the major accretionary wedge faults. Another mechanism must then be proposed to explain these variations.

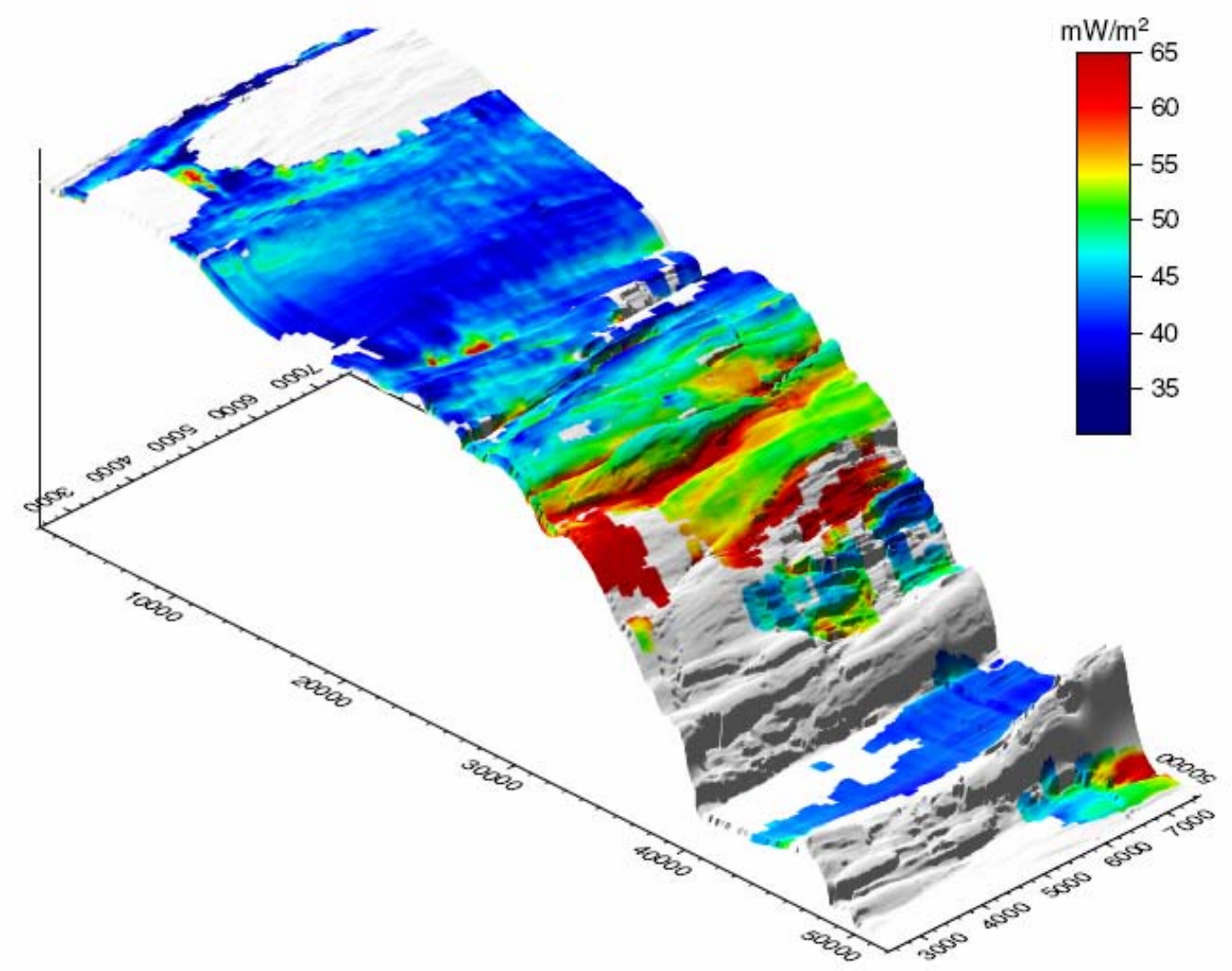

Figure 5. Heat flow deduced from the BSR depth in the 3D box area. White areas denote a missing BSR, where no heat flow can be calculated. Scales in the three directions are different to enlarge details. Location and values of heat flow probe measurements from [41,42] (white triangles) and [43] (black triangles) are also given, and are grouped because they are only a few metres apart of each other. See text for comments. 


\section{Effect of erosion and sedimentation on the heat flow}

To explain the heat flow variations on the wedge, we studied the effect of other phenomena, such as erosion and sediment deposition on a BSR-derived heat flow. In order to provide a comparison frame for the derived heat flow, we computed a basal heat flow using a finite elements modelling program after [45], with a model similar to the one used by [1]. The geometry of the subduction was defined after seismic profiles across the margin where the interplate decollement can be observed [46] and provides the geometry of the finite elements model (figure 7 left). A heat flow of $80 \mathrm{~mW} / \mathrm{m} 2$ was forced in the trench $[42,43,46]$ and at the base of the slab. A subduction velocity of $30 \mathrm{~mm} / \mathrm{yr}$ was used, after $[48,49]$. The thermal conductivity of wedge rocks is the same law than used for the heat flow calculation, with a surface value of about $1.1 \mathrm{~W} \cdot \mathrm{m}^{-1} \cdot \mathrm{K}^{-1}$ and a mean gradient of $0.3 \mathrm{~mW} \cdot \mathrm{m}^{-2} \cdot \mathrm{K}^{-1}$. The heat capacity was calculated

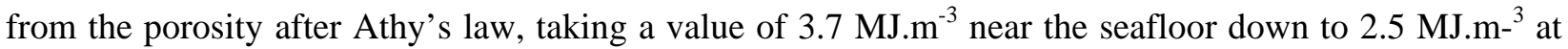
great depth (null porosity). The corresponding material thermal diffusivity is then around $10-12 \mathrm{~m}^{2} \cdot \mathrm{yr}^{-1}$ for surface layers, and is more elevated $\left(15-30 \mathrm{~m}^{2} \cdot \mathrm{yr}^{-1}\right)$ for the consolidated wedge and the slab. The obtained surface heat flow is given in figure 7. The basal heat flow is reduced over the accretionary wedge from 80

$\mathrm{mW} \cdot \mathrm{m}^{-2}$ in the trench to about $45 \mathrm{~mW} \cdot \mathrm{m}^{-2}$ over the forearc basin. This computed heat flow provides a reference heat flow $\Phi_{0}$ that can be used to identify heat flow anomalies over the wedge. Large positive BSR-derived heat flow anomalies can be observed near the slopebreak and in the upper part of the slope, where a recent slump initiated. A negative anomaly can be observed over the slope basin. 


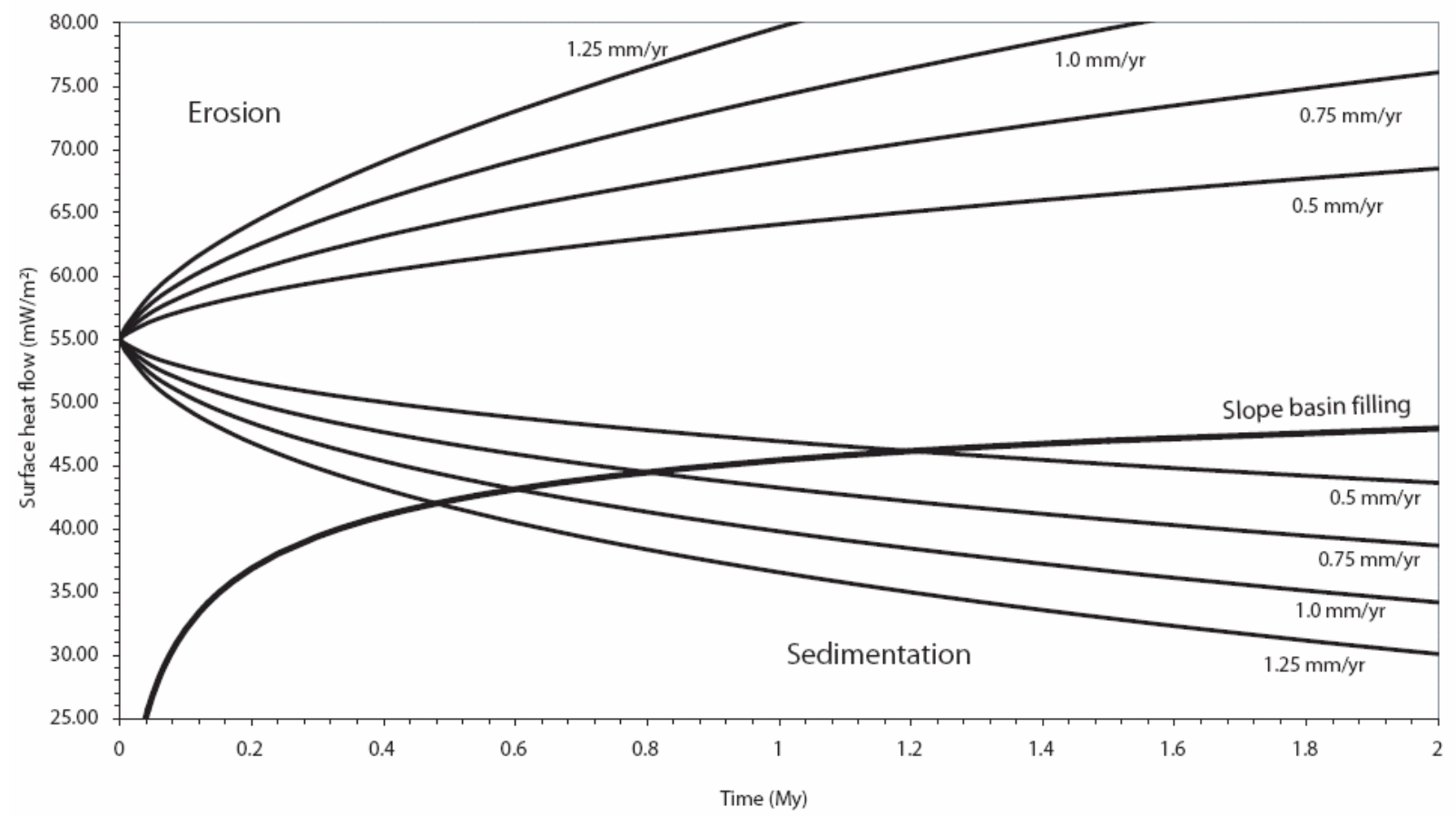

Figure 6. Evolution of the heat flow as a function of time for constant erosion and sedimentation rates. The thick curve corresponds to the flow observed at the surface of the slope basin after a sufficient time to fill it with a $600 \mathrm{~m}$ sedimentary sequence.
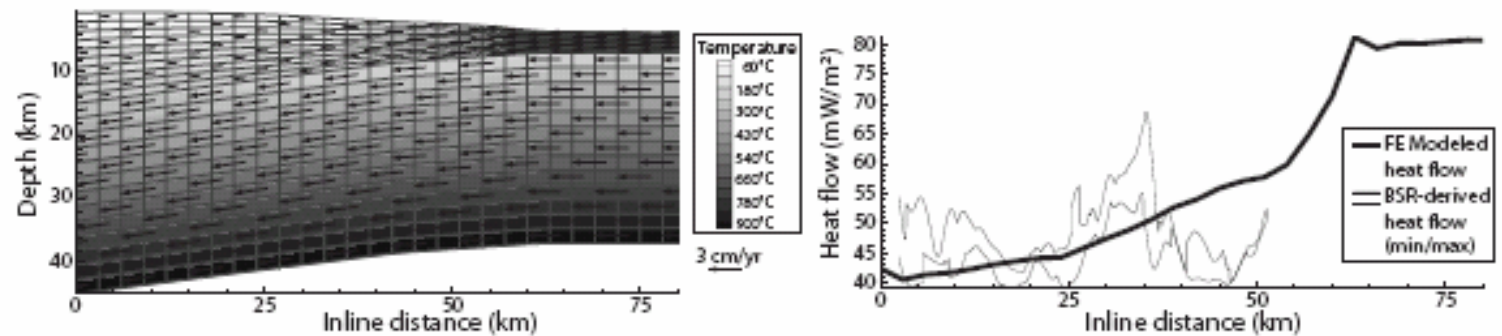

Figure 7. Observed heat flow and reference basal heat flow (right) calculated with a finite-elements model (left). Arrows indicate displacement velocity of the subducting slab. 


\section{Effect of surface processes}

The effect of erosion or sedimentation has already been quantified in many studies (see for example [18-20]). The classical relationship for quantifying the surface heat flow $\Phi_{S}$ as a function of erosion rate is the following $[19,50]$ :

$\Phi_{s}=\Phi_{0}\left[1-4 i 2 \operatorname{erfd}\left(\frac{v t}{2 \sqrt{\kappa t}}\right)\right]$,

with $\Phi_{0}$ basal heat flow, $v$ erosion rate, $t$ time since beginning of erosion and $\kappa$ thermal diffusivity of the ground. However, this formula gives the surface heat flow, whereas we computed the heat flow using a mean temperature gradient between the seafloor and the BSR. The exact expression of temperature as a function of depth as expressed by [50,51]:

$T(Z)=T_{0}+G(z+v t)-\frac{G}{2}\left[(z+v t) \operatorname{erf}\left(\frac{z+v t}{2 \sqrt{\kappa t}}\right)-(z-v t) \exp \left(\frac{-v Z}{\kappa}\right) \operatorname{erf}\left(\frac{z-v t}{2 \sqrt{\kappa t}}\right)\right]$,

with $G$ being the temperature gradient without erosion or sedimentation. It follows that the apparent heat flow between the BSR and the seafloor is:

$\Phi_{B S R}=\Phi_{0}\left[1-\frac{1}{2}\left[\left(1+\frac{v t}{d}\right) \operatorname{erfc}\left(\frac{d+v t}{2 \sqrt{\kappa t}}\right)-\left(1-\frac{v t}{d}\right) \exp \left(\frac{-v d}{\kappa}\right) \operatorname{erf}\left(\frac{d-v t}{2 \sqrt{\kappa t}}\right)-2 \frac{v t}{d}\right]\right]$,

with $d$ being the BSR depth. This equation gives a lower variation of the heat flow than equation 1 , especially when the BSR is deep, because of the delay caused by the diffusion of the heat flow anomaly to the BSR depth. The evolution of this heat flow as a function of time for several erosion/sedimentation rates is represented in figure 6. 


\section{Application to the BSR-derived heat flow}

The age used in the calculation corresponds to the last major change of regime in the accretion history. Seismic profiles correlated with the stratigraphy at the MITI well show a recent $(<1 \mathrm{Ma})$ folding of the forearc basin, that coincides with the beginning of a new phase of accretion. In the eastern Nankai region, the currently active accretionary wedge is separated from an older upper wedge by the Tokai thrust. The volume of the new wedge can then be estimated from seismic profiles, and gives an age for the beginning of accretion. The estimated age of the active wedge is about 740 ky [46], which gives a maximum age for the setup of the present tectonic regime. This estimate is consistent with ages of

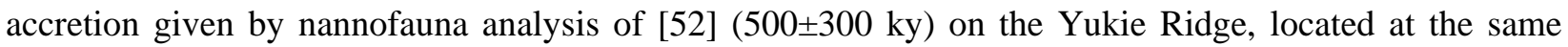
distance from the trench southwestward from the 3D box. We then use a mean age of $600 \mathrm{ky}$. The sensitivity of the calculation to the age is not negligible, and leads to errors of up to $0.15 \mathrm{~mm} \cdot \mathrm{yr}^{-1}$ of the obtained erosion/sedimentation rates within the range of ages given above.

With this age estimate, we calculate the corresponding erosion or sedimentation rates that can create the observed heat flow anomalies using equation 3 . The result is shown in figure 8 . Several domains appear then, described from northwest to southwest. The first domain corresponds to the upper wedge flat, where slight erosion or sedimentation is predicted by the model. Because this domain corresponds to a very shallow BSR, the computed sedimentation and erosion rates may not be reliable. The second domain is an erosional area on the upper part of the wedge slope, where channels and levees can be identified.

In the slope, the heat flow is high in the upper part and decreases rapidly as the seafloor depth increases. It is roughly constant in the slope basin with a value of $41-42 \mathrm{~mW} \cdot \mathrm{m}^{-2}$. This heat flow corresponds to a 1.0-1.2 mm.yr ${ }^{-1}$ deposition rate. At this location, seismic profiles show that the basin is about $600 \mathrm{~m}$ thick. The slope basin is necessarily more recent than $740 \mathrm{ky}$, which is the maximum age of accretion, the mean deposition rate over this period has therefore a minimum value of $0.8 \mathrm{~mm} \cdot \mathrm{yr}^{-1}$, which is consistent with the heat flow-predicted rate. 
Can tectonic events bias the BSR-derived heat flow by bringing the BSR far from its equilibrium position ? Horizontal displacements have negligible effects on the heat flow, and vertical motions at first only change pore pressure. This change is immediate compared to the diffusion of a temperature change. As a consequence, the BSR reacts more rapidly to a tectonic event, in comparison to erosion and sedimentation. The BSR position is probably not far from its equilibrium when only affected by uplift or subsidence. The heat flow anomalies calculated from the BSR depth are probably not much biased by tectonic motions. 

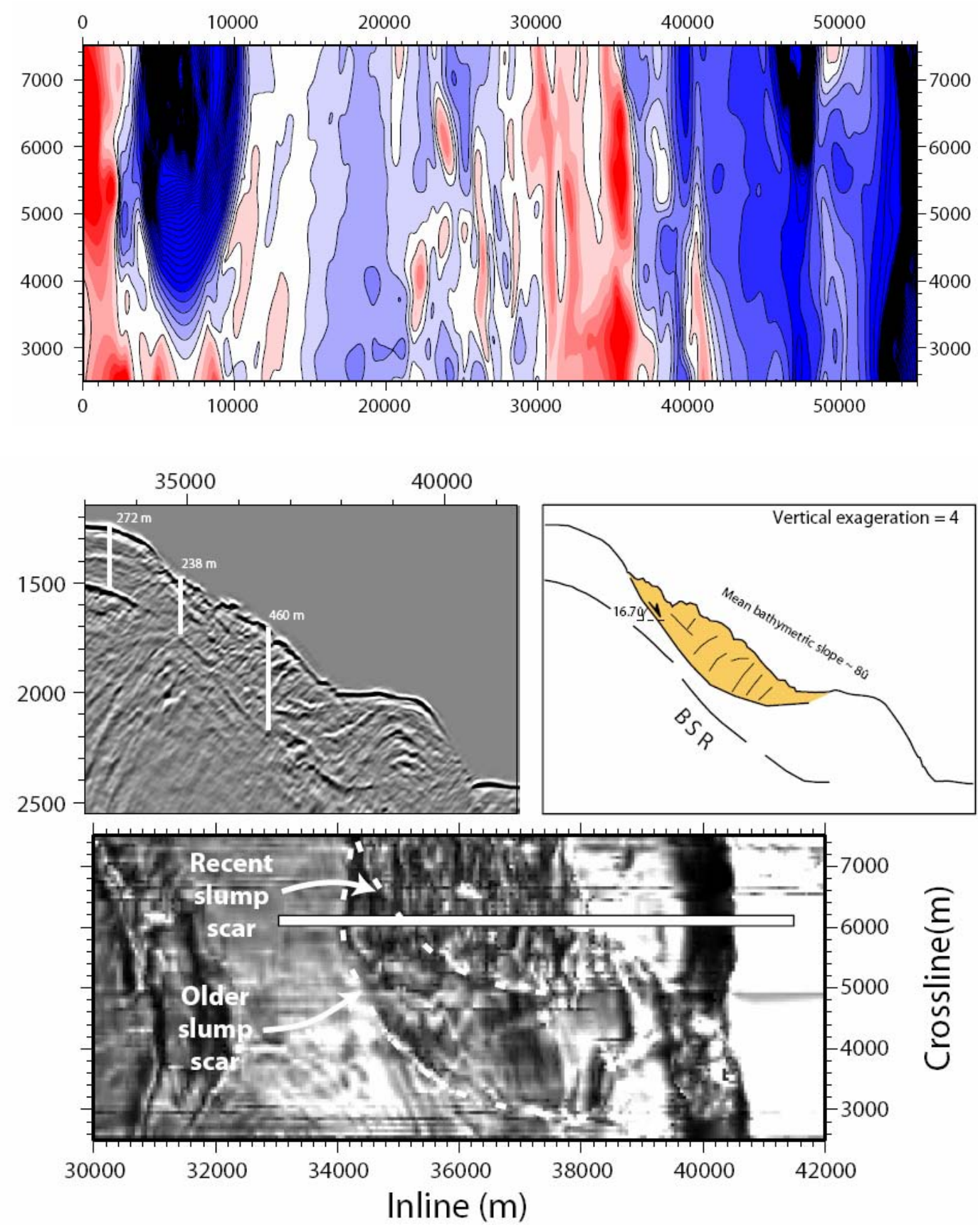

Figure 8. Up: Erosion and sedimentation rates map in the 3D box area. Blue zones correspond to sedimentation and red zones to erosion. Rates are in $\mathrm{mm} / \mathrm{yr}$. The hatched area corresponds to a less than $200 \mathrm{~m}$ deep BSR. Since the heatflow is not completely reliable in this area, cautious interpretation of the rates has to be done. Dashed box indicate the location of the enlargement below. Middle: Cross-section in the slope, showing the BSR and the slump slip surface. Down: Enlargement of the upper sedimentation map, with P-waves reflectivity of the seafloor in the slope area, showing the location of the channel. The location of the upper profile is marked by a bar. Three slumping areas can be delimited: one current on the top of the slope, one recent and one older lower in the slope, suggesting that slumping is a common and repeated process over the slope. 


\section{Cause of the heat-flow anomalies}

We have seen that heat flow anomalies inferred from BSR depth do not correlate well with zones where seafloor manifestations of methane emissions are found. These manifestations are found, in particular, on the hanging wall of Tokai and Kodaiba faults. The BSR is absent above Tokai. Thus, we cannot exclude that a heat flow anomaly may be associated with these vents. Around Kodaiba, BSR-derived heat flow is close to the background value but the BSR is patchy. The absence (or relative weakness) of the BSR below cold seep sites is a puzzling observation. One possible explanation is that gas migrated out of the sediment during the recent past, possibly during a transient flow event with associated high heat flow.

As previously calculated, erosion or sedimentation since the last major tectonic event can explain the heat flow anomalies. On the slope basin, the sedimentation rate calculated from the heat flow matches the mean deposition rate observed. On seismic profiles, zones of heat flow-predicted erosion also coincide with active erosion on the part located above the wedge slope, with channels and a few levees observed on the basin area near the slope. In the slope, a large positive heat flow anomaly is followed downwards by a large negative anomaly. These anomalies correspond to a slump, that can be observed on seismic profiles (figure 8), that has approximatively a $5 \mathrm{~km} 3$ volume inside the 3D box. This type of anomaly was previously observed by well temperature measurements on the Cascadia wedge by [40].

The sliding surface is clearly defined above the BSR (see figure 8), and the BSR has not yet responded to the change of seafloor geometry. The temperature perturbation due to the sliding has not yet been diffused down to the depth of the BSR, about 80-100 $\mathrm{m}$ below the sliding surface. Sliding thus

occured less than an estimated age of 1700 years ago, using a mean thermal diffusivity value of $11 \mathrm{~m}^{2} \cdot \mathrm{yr}^{-1}$. The BSR geometry was used to reconstitute the original seafloor position. With this original geometry, we used the approximation of [53] to calculate the necessary conditions to initiate the sliding, for a typical material following Byerlee's law $(\mu=0.85)$ and for clay $(\mu=0.4)$. The factor of safety in the two cases is 
respectively equal to 3.41 and 1.65 . It has been suggested that an excess pore pressure can trigger a landslide, for example when a BSR is destabilised and therefore releases the water contained in the hydrates. The corresponding fluid excess pore pressure coefficient (see [40]) that may cause the sliding is respectively $\sigma^{*}=0.67$ or $\sigma^{*}=0.37$, with $\sigma^{*}=0$ corresponding to hydrostatic pore pressure and $\sigma^{*}=1$ to lithostatic pore pressure. In terms of ground motion, the peak acceleration that can trigger the sliding is respectively $0.60 \mathrm{~g}$ and $0.16 \mathrm{~g}$. Given the proximity of the seismogenic zone and possible splay faults (Kodaiba and Tokai), these acceleration values are reached during every major earthquake recorded in the area, occuring about every 180 years [54]. If both pore fluid overpressure and ground motion occur during an earthquake, the acceleration caused by any of the most recent earthquakes alone can have triggered this sliding, without fluid overpressure. On figure 8 , the seafloor reflectivity shows the recent slump, but also an older slump probably caused by a previous earthquake. Slumping is then here a repeated process, and is therefore most probably caused by the regional strong seismicity. Over a long enough period, slumping have the same effect than erosion of the upper slope part and redeposition on the lower slope part, and can then be interpreted as the cause of the heat flow anomalies. Slumping is a discontinuous process but the erosion and sedimentaiton rates calculated reflect in average the balance between slide initiation areas and redeposition areas. Areas of observed sedimentation and erosion match the heat flow-predicted erosion and sedimentation over most of the wedge, where the heat flow can be confidently calculated. Sedimentation and erosion are then sufficient to explain heat flow anomalies revealed by the BSR over the Eastern Nankai Trough without any wedge-scale fluid circulation. The near-surface thermal regime of the wedge in this area is then probably dominated by surface processes and not by fluid circulation along faults. The origin of these processes is the tectonic activity of the margin. The presence of a large oceanic ridge under the wedge, the Paleozenisu Ridge, has been suggested from sandbox modelling experiments [55], magnetic anomalies [56] and MCS survey [26,46]. It has an effect on the wedge deformation, and may be the cause of local uplifts, enabling erosion by channels and building of potentially unstable slopes. It also interplays with the seismic cycle [26], that is responsible for the trigerring of submarine mass movements observed in the 3D survey area. 
From this analysis, we cannot exclude that fluid flow is contributing to the heat flow distribution on Nankai. However, we show that along the profile studied, erosion and deposition yield a stronger signal and that it would be difficult to isolate and quantify the effect of fluid flow. This finding is consistent with earlier observations at the deformation front [10]. The average heat flow there is not significantly increased, although some of the seepage sites where associated with very local (1 to $10 \mathrm{~m}$ size) temperature anomalies. Our result is also consistent with budget calculations showing that heat flow anomalies related to fluid flow in accretionary wedges are necessarily local and transient (e.g. [57]). Other sections of the Tokai margin where more vigorous seepage is observed may have associated heat flow anomalies.

\section{Conclusion}

We calculated a heat flow over the eastern part of the Nankai wedge using the BSR as a temperature indicator by assuming that the sediment types are the same as those observed on the central part of the Nankai wedge. This heat flow presents strong anomalies in comparison with the expected heat flow after a simple wedge model. Since the heat flow anomalies are not distributed with respect to active wedge faults and fluid venting sites, it is unlikely that fluid circulation along major wedge faults is the cause of the BSR-derived heat flow anomalies. We propose that these heat flow anomalies are due to erosion and sedimentation. Assuming that the tectonic and therefore erosional regime last changed about 600 ky ago, which corresponds to the beginning of the accretion of the presently active wedge, we calculated erosion and sedimentation rates that explain the BSR-derived heat flow anomalies. Areas of present erosion and sedimentation observed on seismic profiles match the heat flow-predicted areas. In particular on a slope basin where a mean sedimentation rate can be calculated from seismic images and datations, it matches the heat flow-predicted sedimentation rate. The erosion and sedimentation map on the wedge slope also reflects the sliding initiation and redeposition areas of slumps. These surface 
processes are the result the tectonic regime over the Eastern Nankai margin. A large oceanic ridge is currently subducting under the margin, causing uplifts of the forearc domain and steepening of the margin slope, and also probably influencing earthquake rupture geometry. Fluid flow may occur in this area, but only episodically or with a low flow rate that does not significantly affect the BSR-derived heat flow.

\section{Acknowledgements}

We thank the N/O Nadir crew and his captain Rémi Balcon for their very good work during the survey. We also thank Jean-Paul Foucher for fruitful discussions, and are very grateful to Louis Géli and Graham K. Westbrook for their reviews and suggestions to improve the manuscript. This work was funded by Ifremer and by INSU through the "ad-hoc ocean" fund. We are also grateful to the partners of the DIG consortium (Ecole des Mines de Paris) for partial support of this work. 


\section{References}

[1] M.G. Langseth, G.K. Westbrook, and M. Hobart, Contrasting geothermal regimes of the Barbados Ridge accretionary complex, J. Geophys. Res., 95, 8829-8843, 1990.

[2] X. Le Pichon, P. Henry, and S. Lallemant, Water flow in the Barbados accretionary complex, J. Geophys. Res., 95, 8945-8967, 1990.

[3] I.J. Ferguson, G.K. Westbrook, M.G. Langseth, and G.P. Thomas, Heat-flow and thermal models of the Barbados Ridge accretionary complex, J. Geophys. Res., 98, 4121-4142, 1993.

[4] K. Wang, R.D. Hyndman, and M. Yamano, Thermal regime of the Southwest Japan subduction zone: effects of age history of the subducting plate, Tectonophysics, 248, 53-69, 1995.

[5] A. Taira, I. Hill, J. Firth, U. Berner, W. Brückmann, T. Byrne, T. Chabernaud, A. Fisher, J.-P. Foucher, T. Gamo, J. Gieskes, R.D. Hyndman, D. Karig, M. Kastner, Y. Kato, S. Lallemant, R. Lu, A. Maltman, G.F. Moore, K. Moran, G. Olaffson, W. Owens, K. Pickering, F. Siena, E. Taylor, M. Underwood, C. Wilkinson, M. Yamano, and J. Zhang,, Initial report Leg 131 , Proc. Ocean Drilling Program, 1991.

[6] T.A. Minshull, and R.S. White, Sediment compaction and fluid migration in the Makran accretionary prism, J. Geophys. Res., 94, 7387-7402, 1989.

[7] J.-P. Foucher, X. Le Pichon, S. Lallemant, M.A. Hobart, P. Henry, M. Benedetti, G.K. Westbrook, G. K., and M.G. Langseth, Heat-flow, tectonics and fluid circulation at the toe of the Barbados Ridge accretionary prism, J. Geophys. Res., 95, 8859-8867, 1990.

[8] G. Zwart, J.C. Moore, and G.R. Cochrane, Variations in temperature gradients identify active faults in the Oregon accretionary prism, Earth Planet. Sci. Lett., 139, 485-495, 1996.

[9] B. Carson, and E.J. Screaton, Fluid flow in accretionary prisms: Evidence for focused, timevariable discharge, Rev. Geophys., 36, 329-351, 1998. 
[10] P. Henry, J.-P. Foucher, X. Le Pichon, M. Sibuet, K. Kobayashi, P. Tarits, N. Chamot-Rooke, T. Furuta, and P. Schulteiss, Interpretation of temperatures from the KAIKO-Nankai cruise: Modeling of fluid flow in clam colonies, Earth Planet. Sci. Lett., 109, 335-371, 1992.

[11] P. Henry, S. Lallemant, K. Nakamura, U. Tsunogai, S. Mazzotti, and K. Kobayashi, Surface expression of fluid venting at the toe of the nankai wedge and implications for flow paths, Marine Geol., 187, 119-143, 2002.

[12] K. Kobayashi, Tectonic significance of the cold seepage zones in the eastern Nankai accretionary wedge - an outcome of the 15 years KAIKO projects, Marine Geol., 187, 3-30, 2002.

[13] K.A. Kvenvolden, Gas hydrates - geological perspective and global change, Rev. Geophys., 31, 173-187, 1993.

[14] T.H. Shipley, M.H. Houston, R.T. Buffer, F.J. Shaub, K.J. Mac Millen, J.W. Ladd, and J.L. Worzel, Seismic evidence for widespread possible gas hydrate horizons on continental slopes and rises, AAPG Bull., 63, 2204-2213, 1979.

[15] M. Yamano, S. Uyeda, Y. Aoki, and T.H. Shipley, Estimates of heat flow derived from gas hydrates, Geology, 10, 339-343, 1982.

[16] R.D. Hyndman, J.-P. Foucher, M. Yamano, A. Fisher, and the scientific team of Ocean Drilling Program Leg 131, Deep-sea bottom-simulating-reflectors: calibration of the base of hydrate stability field as used for heat flow estimates, Earth Planet. Sci. Lett., 109, 289-301, 1992.

[17] L. Géli, J.-L. Turon, D. Aslanian, Y. Balut, P. Beuzart, P. Cochran, J. Francheteau, F. Harmegnies, J.-Y. Landuré, R. Le Suavé, A. Mazaud, E. Michel, A. Normand, J.-J. Pichon, and I. Vlastelic, Deep-penetration heat flow probes raise questions about interpretations from shorter probes, Eos, Transactions Am. Geophys. Union, 82, 317-320, 2001.

[18] D.L. Turcotte, and J.L. Ahern, On the thermal and subsidence history of sedimentary basins, J. Geophys. Res., 82, 3762-3766, 1977.

[19] M.G. Langseth, M.A. Hobart, and K. Horai, Heat flow in the Bering Sea, J. Geophys. Res., 85, 3740-3750, 1980. 
[20] I. Hutchinson, The effects of sedimentation and compaction on oceanic heat flow, Geophys. J. Roy. Astron. Soc., 82, 439-459, 1985.

[21] G. Pascal, S. Kuramoto, S. Lallemant, H. Tokuyama, V. Martin, M. Noble, S.C. Singh, H. Nouzé, H., and The SFJ onboard scientific party, French - japanese 3D seismic reflection survey on the eastern Nankai accretionary complex and seismogenic zone, Eos, Transactions AGU Fall Mtg Suppl., 81(48), T52D-06, 2000.

[22] P. Thierry, G. Lambaré, P. Podvin, and M. Noble, 3-D preserved amplitude prestack depth migration on a workstation, Geophysics, 64, 222-229, 1999.

[23] P. Jousset, P. Thierry, and G. Lambaré, Reduction of 3-D acquisition footprint in 3-D migration/inversion, in: SEG 69th Ann. Internat. Mtg. Expanded Abstracts, Houston, USA, 1999, pp. 1354-1357.

[24] K. Al-Yahya, Velocity analysis by iterative profile migration, Geophysics 54, 718-729, 1989.

[25] H. Tokuyama, J. Ashi, W. Soh, S. Kuramoto, and Y. Ikeda, Active submarine faults off Tokai results from the Japan-France KAIKO-Tokai project, Univ. Tokyo Press, 1999.

[26] S. Mazzotti, S.J. Lallemant, P. Henry, X. Le Pichon, H. Tokuyama, N. and Takahashi, Intraplate shortening and underthrusting of a large basement ridge in the eastern Nankai subduction zone, Marine Geol., 187, 193-202, 2002.

[27] J.-P. Foucher, H. Nouzé, and P. Henry, Observation and tentative interpretation of a double BSR on the Nankai slope, Marine Geol., 187, 161-175, 2002.

[28] A.Y. Golmshtok, A.D. Duchkov, D.R. Hutchinson, and S.B. Khanunaev, Heat flow and gas hydrates of the Baikal Rift zone, Int. J. Earth Sc., 89, 193-211, 2000.

[29] C. Berndt, J. Mienert, M. Vanneste, S. Bünz, and P. Bryn, Submarine slope-failure offshore Norway triggers rapid gas hydrate decomposition, in: 4th int. conf. on gas hydrates proc., Yokohama, Japan, 2002. 
[30] H. Takahashi, T. Yonezawa, and Y. Takedomi, Exploration for natural hydrate in Nankai trough wells offshore Japan, in Offshore Technology Conference 2001, Houston, USA , 2001, ref. OTC 13040.

[31] G.S. Dickens, and M.S. Quinby-Hunt, Methane hydrate stability in seawater, Geophys. Res. Lett., 21, 2115-2118, 1994.

[32] R.J. Bakker, Improvement in clathrate modelling II: the H2O-CO2-CH4-N2-C2H6 fluid system, in: J.-P. Henriet and J. Mienert (ed.), Gas hydrates: relevance to world margin stability and climate changes, Geol. Soc. London Spec. Publ. 137, 75-105, 1998.

[33] E.D. Sloan Jr, Clathrate hydrates of natural gases (2nd edn), Marcel Dekker, Inc, New York, USA, 1998.

[34] U. Tsunogai, N. Yoshida and T. Gamo, Carbon isotopic evidence of methane oxidation through sulfate reduction in sediment beneath cold seep vents on the seafloor at Nankai Trough, Mar. Geol. 187, 145-160, 2002.

[35] R. Matsumoto, Comparison of Marine and Permafrost Gas Hydrate: Examples from Nankai Trough and Mackensie Delta, in: 4th int. conf. on gas hydrate proc., Yokohama, Japan, 2002.

[36] R. Matsumoto, Y. Takedomi, and H. Wasada, Exploration of marine gas hydrate in Nankai Trough, offshore central Japan, in: AAPG Ann. Mtg Exp. Abstracts, Denver, USA, 2001, p. 8458.

[37] H. Tomaru, R. Matsumoto, T. Uchida, and H. Lu, Hydrate formation system from the pore water analysis in Nankai trough, in: AAPG Ann. Mtg Exp. Abstracts, Denver, USA, 2001, p. 8460.

[38] I. Grevemeyer, and H. Villinger, Gas-hydrate stability and the assessment of heat-flow through continental margins, Geophys. J. Int., 145, 647-660, 2001.

[39] G.F. Moore, A. Taira, A. Klaus, K. Becker, L. Becker, B. Boeckel, B.A. Cragg, P.A. Dean, C.L. Fergusson, P. Henry, S. Hirano, T. Hisamitsu, S. Hunze, M. Kastner, A.J. Maltman, J.K. Morgan, Y. Murakami, D.M. Saffer, M. Sanchez-Gomez, E.J. Screaton, D.C. Smith, A.J. Spivack, J. Steurer, H.J. Tobin, K. Ujiie, M.B. Underwood, and M. Wilson, Initial report Leg 190 , Proc. Ocean Drilling Program, 2000. 
[40] E.E. Davis, R.D. Hyndman, and H. Villinger, Rates of fluid expulsion across the Northern Cascadia accretionary prism: constraints from new heat flow and multichannel seismic reflection data, J. Geophys. Res., 95, 8869-8889, 1990.

[41] J. Ashi, H. Tokuyama, and A. Taira, Distribution of methane hydrate BSRs and its implication for the prism growth in the Nankai Trough, Marine Geol. 187, 177-191, 2002.

[42] M. Kinoshita, and M. Yamano, Heat flow distribution in the Nankai Trough region, in: H. Tokuyama and S. Shcheka (ed.), Geology and geophysics of the Philippine Sea, pp. 77-86, Terra Scientific Publishing Company, Tokyo, 1995.

[43] M. Yamano, T. Yamagata, and M. Kinoshita, Compilation of the heat flow data in Northwestern Pacific area, in Proceedings of the 1997 Japan Earth and Planetary Science Joint Meeting, Nagoya, Japan, 1997, p. 245.

[44] M. Joshima, and S. Kuramoto, Heat flow measurements in the off Tokai area, Geological Survey of Japan Cruise report, 24, 81-86, 1998.

[45] O.C. Zienkiewicz, and R.L. Taylor, The finite element method (5th edn), Butterworth-Heinemann, Oxford, UK, 2000.

[46] V. Martin, Structure et tectonique du prisme de Nankai dans la zone Tokai par imagerie sismique en trois dimensions, PhD thesis (in french), Université Paris-sud, 2003.

[47] M. Yamano, J.-P. Foucher, M. Kinoshita, A. Fischer, and R.D. Hyndman, Heat flow and fluid flow regime in the western Nankai accretionary prism, Earth Planet. Sci. Lett., 109, 451-462, 1992.

[48] X. Le Pichon, F. Pollitz, M. Fournier, J.-P. Cadet, S. Lallemant, and N. Chamot-Rooke, Distribution of shortening landward and oceanward of the eastern Nankai trough due to the Izu-Ogasawara ridge collision, Earth Planet. Sci. Lett., 137, 145-156, 1996b.

[49] S. Mazzotti, L’arc insulaire japonais: déformation transitoire et permanente liée à la subduction et à la collision, PhD thesis (in french), Université Paris-sud, 1999.

[50] H.S. Carslaw and J.C. Jaeger, Conduction of heat in solids (2nd edn.), Clarendon press, Oxford, UK, 1959. 
[51] A.E. Benfield, The effect of denudation on underground temperatures, J. App. Phys., 20, 66-70, 1949.

[52] S.E. Lallemand, G. Glaçon, A. Lauriat-Rage, A. Fiala-Médioni, J.-P. Cadet, C. Beck, M. Sibuet, J.T. Iiyama, H. Sakai, and A. Taira, Seafloor manifestations of fluid seepage at the top of a 2000metre-deep ridge in the Eastern Nankai accretionary wedge: Long-lived venting and tectonic implications, Earth Planet. Sci. Lett., 109, 333-346, 1992 b.

[53] A.W. Bishop, The use of slip circle in stability analysis of slopes, 1st european conference on slope stability of Earth slopes proc., Stockholm, Sweden, 1954, pp.1-13.

[54] M. Ando, Source mechanism and tectonic significance of historical earthquakes along the Nankai Trough, Japan, Tectonophysics 27, 119-140, 1975.

[55] S.E Lallemand, J. Malavieille, S. and Calassou, Effects of oceanic ridge subduction on accretionary wedges: experimental modeling and marine observations, Tectonics, 11, 1301-1313, 1992a.

[56] X. Le Pichon, S. Lallemant, H. Tokuyama, F. Thoué, P. Huchon, and P. Henry, Structure and evolution of the backstop in the eastern Nankai Trough area (Japan): implications for the soon-tocome Tokai earthquake, Isl. Arc, 5, 440-454, 1996a.

[57] Y. Shi and C.-Y. Wang, Model studies of advective heatflow associated with compaction and dehydration in accretionary prisms, J. Geophys. Res., 99, 9319-9325, 1994. 